\title{
A École Polytechnique de Paris: mitos, fontes e fatos
}

\author{
The École Polytechnique of Paris: myths, sources and facts
}

\author{
Marcello Amadeo* \\ Gert Schubring ${ }^{* *}$
}

\begin{abstract}
Resumo
A École Polytechnique de Paris foi um grande marco para o ensino da matemática e se destaca em diversos sentidos. Pretendemos neste artigo analisar algumas contribuições que tradicionalmente são creditadas à Escola Politécnica e contrastar com pesquisas mais recentes sobre esses assuntos. Buscamos averiguar a veracidade desses relatos associados às produções matemáticas da escola e rever em que contexto elas foram publicadas, quais as suas repercursões e o que dizem os estudos mais atuais. As contribuições francesas do século XIX, incluindo o final do século XVIII, foram fundamentais para o desenvolvimento da matemática. A noção de rigor na matemática passava por profundas mudanças. Os paradigmas clássicos eram confrontados com as novas ferramentas provindas do método analítico. A difusão e aplicação do método analítico na geometria, na mecânica e no cálculo infinitesimal foi um passo fundamental para caracterizar muitas práticas matemáticas que temos hoje. A análise matemática aproximava-se aos poucos da forma como hoje se configura. As mudanças que a matemática atravessava e as principais contribuições da escola francesa possuem uma relação muito forte na história da matemática. Nosso objetivo é contrastar os mitos difundidos a respeito da escola com os fatos na nova historiografia. Novas pesquisas sobre a história da École Polytechnique (em seguida: EP), em particular desde o Bicentenário da Revolução Francesa, têm revelado novas fontes em arquivos com as novas metodologias. Complementando os trabalhos mais recentes, utilizamos o próprio Journal de l'École Polytechnique, em seus primeiros anos de publicação, para buscarmos publicações diretas da escola que atestem nossas informações.
\end{abstract}

Palavras-chave: História do Ensino da Matemática. Relação entre Ensino e Pesquisa. Escola Politécnica. Monge. Laplace.

\begin{abstract}
The École Polytechnique of Paris constituted a milestone for the teaching of mathematics, being emblematic in several respects. In this article, we intend to analyze some contributions that are traditionally credited to the Polytechnic School and contrast them with more recent research on these topics. We seek to ascertain the veracity of these reports associated with its mathematical productions and review the context in which they were published, including their repercussions and the results of recent studies. French contributions of the nineteenth century, including the late eighteenth century, were instrumental in the development of mathematics. The notion of rigor in mathematics was going through profound changes. The classical paradigms were faced with new conceptions emerging from the analytical method. The dissemination and application of the analytical method in geometry, mechanics, and infinitesimal calculus was a crucial step to elaborate many mathematical practices we

\footnotetext{
* Mestre pelo Programa de Pós-Graduação em Ensino de Matemática do Instituto de Matemática da Universidade Federal do Rio de Janeiro (IM/UFRJ). Professor assistente do Instituto de Aplicação Fernando Rodrigues da Silveira (CAp-UERJ), Rio de Janeiro/RJ. Endereço para correspondência: Rua Santa Alexandrina, 288, Departamento de Matemática e Desenho, Rio Comprido, Rio de Janeiro/RJ, CEP: 20261-232. E-mail: marcello.amadeo@gmail.com.br.

** Doutor em Matemática pela Universidade de Bielefeld, Alemanha. Professor visitante da Universidade Federal do Rio de Janeiro (UFRJ), Rio de Janeiro/RJ. Endereço para correspondência: Rua Benjamin Constant, 92, ap. 601, Glória, Rio de Janeiro, RJ, Brasil, CEP: 20241-150. E-mail: gert.schubring@uni-bielefeld.de.
} 
have today. The mathematical analysis was slowly approaching the form it has developed nowadays. There is a very strong connection in the history of mathematics between the changes that happened during the late XVIII / beginning XIX century and the contributions of the French school. Our goal is to contrast some of the widespread myths about the school with the results established by the new historiography. New research on the history of the École Polytechnique (abbreviated as EP), particularly since the Bicentennial of the French Revolution, have revealed new sources in archives, with new methodologies. By supplementing the more recent investigations, we use the Journal de l'École Polytechnique in its first years, to seek publications directly from the school providing evidence for our claims.

Keywords: History of Mathematics Education. Relation between Teaching and Research. École Polytechnique. Monge. Laplace.

\section{Introdução}

A Escola Politécnica (EP) de Paris foi berço de notáveis matemáticos do século XIX, sendo, portanto, uma instituição bastante influente nas comunidades matemáticas, principalmente na França. Diversos nomes da história da matemática francesa tiveram alguma participação na escola: Gaspard Monge (1746-1818) foi um importantíssimo administrador da escola, fundamental para a construção da geometria descritiva; Joseph-Louis Lagrange (1736-1813) também teria sido professor da escola e suas notas de aula teriam dado origem a uma de suas mais importantes publicações; Sylvestre-François Lacroix (1765-1843) foi professor e também um dos autores de livro-texto mais bem sucedido na história do cálculo diferencial e integral e sua obra foi utilizada para muito além de suas aulas na Escola Politécnica; Augustin-Louis Cauchy (1789-1857), quando professor da escola, foi pioneiro na fundamentação da análise matemática em conceitos de rigor.

Esses autores são alguns exemplos que ilustram como a Escola Politécnica parisiense estava envolvida com alguns importantes desenvolvimentos da matemática francesa do início do século XIX. A qualidade dos trabalhos produzidos pela escola fez com que ela ganhasse, assim, um respeito do mais alto nível na história da matemática. A repercussão desses trabalhos leva-nos a crer que deveria existir um ambiente que favorecesse essa produção.

A escola é, então, frequentemente considerada uma instituição que promovia o desenvolvimento da matemática. Em um relato de 1810 ao Imperador Napoleão, o astrônomo Delambre faz uma primeira avaliação relevante sobre a possibilidade de a escola ser uma instituição superior da matemática. Ele a apresenta como uma "école spéciale des mathematiques", ou seja, uma instituição do ensino superior para formar matemáticos (DELAMBRE, 1810, p. 41). A instituição também é vista não apenas pela sua formação de engenheiros, mas também por privilegiar a pesquisa em matemática, de modo que a EP passa a ser vista como um berço do nosso modelo atual de instituição superior de ensino, em que o 
professor tem uma dupla tarefa de conciliar as suas regências de aula com as suas próprias pesquisas.

\section{Relato tradicional}

Antes de nos aprofundarmos nas pesquisas atuais, vamos rever algumas concepções tradicionais a respeito da Escola Politécnica. Apoiamo-nos, em primeiro momento, nos livros História da Matemática, de C. Boyer (1989) e Introdução à História da Matemática, de H. Eves (2004). Nesses textos vemos diversas citações à EP. O século XIX é recheado de matemáticos franceses que tiveram, de alguma maneira, uma ligação com a escola. Esses livros, bem como diversos outros de história da matemática, seguem uma tradição de descrição biográfica, em que se descrevem vida e obra dos matemáticos individualmente. $\mathrm{O}$ ambiente em que são descritos costuma ser apresentado de maneira indireta, dentro da descrição particular de cada matemático. Por vezes, faz-se crer que a produção matemática se resume a um esforço individual, uma vez que muitos nomes que não tiveram grandes repercussões são omitidos.

Nesse sentido, os matemáticos escolhidos para descrever a história da matemática geram uma concepção de que a matemática seria composta de gênios singulares. Pouco se valorizam nesses livros as contribuições menores dos coadjuvantes da história da matemática. As práticas de cada época também ficam resumidas aos trabalhos desses protagonistas.

Para formularmos uma análise complementar a esses textos, utilizaremos livros menos usuais de história da matemática, mas que nos oferecem um panorama mais abrangente da matemática e dos matemáticos dessa época. A abordagem sucinta de D. Struik em História Concisa da Matemática (1987) é um bom exemplo da historiografia tradicional supracitada, mas com algumas diferenças significativas. Apesar de ser um texto bastante breve, traz algumas contribuições relevantes pela sua abordagem social. Ele insere a produção matemática levando em consideração as transformações sociais e políticas em que estavam inseridas.

O último texto que nos servirá de apoio para essa análise tradicional é o de Felix Klein (1849-1925), Development of Mathematics in the 19th Century (1979). Klein também traz contribuições significativas para a historiografia do século XIX, pois trata-se de um autor que viveu a matemática do final desse século. Portanto, o seu livro sobre o desenvolvimento da matemática deste período é uma fonte de testemunho. A EP, por exemplo, fica apresentada como a causa da alta produção dos matemáticos franceses. Os matemáticos do século XIX 
contribuíram para difundir já alguns mitos sobre a EP. Klein, portanto, trataria de disseminar algumas dessas concepções, que colocaremos em questão.

Graças, em particular, ao Bicentenário da Revolução Francesa, um grande número de novos estudos sobre a história da EP foi publicado, modificando consideravelmente os relatos tradicionais. Vale destacar a reedição do livro de Fourcy de 1828, a primeira história da EP, por Jean Dhombres, acrescentado por muitas análises e anexos (DHOMBRES, 1998); Janis Langins, especializado em pesquisas nos arquivos da EP, com um livro sobre as origens da fundação da EP (LANGINS, 1987); Christian Gilain com suas pesquisas sobre Cauchy o sobre os registros do ensino na EP (GILAIN, 1989); os três volumes de Grattan-Guinness sobre a matemática francesa entre 1800 e 1840, com extensas análises sobre os matemáticos na EP (GRATTAN-GUINNESS, 1990); a série de publicações de SABIX, a associação de amigos da EP, em particular os números 11 e 12 com mais documentos sobre a fundação da EP (BELHOSTE, 1994) e as atas das reuniões do Conselho da EP entre 1794 e 1795 (DOOLEY, 1994); as pesquisas de Schubring sobre as pressões das escolas de aplicações quanto ao papel de formação da EP, as crises provocadas e a volta induzida ao método sintético (SCHUBRING, 2004) ${ }^{1}$; a biografia de Cauchy por Belhoste, primeiro em francês (BELHOSTE, 1985) e depois em inglês (BELHOSTE, 1991); as biografias de Fourier por Grattan-Guinness e Ravetz (1972) e por Dhombres e Robert (1998).

\section{Revolução Francesa e a criação da Escola Politécnica}

Durante o século XVIII, a França atravessava transformações profundas em toda sua estrutura organizacional. O Antigo Regime, liderado pela nobreza e pelo clero, privilegiava apenas as classes mais abastadas. Os cargos de engenheiros militares, por exemplo, eram reservados à aristocracia. No entanto, essa estrutura atravessava uma forte crise econômica: o tesouro nacional encolhia, os impostos aumentavam. "A França, que nos anos de fartura praticamente transbordava com os mais finos alimentos, sofreu um período de fome nacional em dezesseis dos cem anos do século 18, que terminou em revolução.” (BLAINEY, 2008, p. 224). As cidades, em especial Paris, foram sobrecarregadas por conta do êxodo rural provocado por essas crises no campo. Por consequência, a falta de saneamento e, principalmente, a escassez de alimento para a população geravam uma insatisfação nacional. Esses fatores, aliados ao florescimento intelectual proveniente do Iluminismo, favoreceram os

\footnotetext{
${ }^{1}$ Um resumo deste livro, publicado em alemão, encontra-se no capítulo IV do livro (SCHUBRING, 2005).
} 
movimentos revolucionários do final do século XVIII. Eles tinham como propósito desassociar essas duas classes - a nobreza e o clero - de todas as esferas de dominação.

A revolução, portanto, afetou diretamente as diversas instituições e os modelos de ensino francês. O projeto do Marquês de Condorcet (1743 - 1794), de $1792^{2}$ é um exemplo de como essas mudanças afetaram o ensino, pois sua elaboração foi fundamental para a edificação do modelo da educação francesa. $\mathrm{O}$ ensino não deveria ser restrito a nenhuma classe social, assim, deveria ser laico, isto é, sem relações com a Igreja e de responsabilidade exclusiva do Estado. Esse novo modelo valorizaria a meritocracia como forma de acesso. A educação deveria ser uma responsabilidade do Estado por ser entendido que ela seria condição necessária para seu bom funcionamento.

A Revolução Francesa via no ensino duas formas de defender seus ideais. Uma delas seria defender a igualdade e a liberdade no sentido de destruir as antigas estruturas feudais. Tinha-se como objetivo reconstruir o modelo de educação vigente, tornando-o público, possível a todos, sem discriminação social. E, consequentemente, foi uma forma de garantir o progresso do novo Estado francês.

A segunda forma é relacionada à proposta de Condorcet, que teve uma importante contribuição no ensino das ciências. Seu plano estava voltado para o progresso incorporando as ciências ao ensino. Salvo algumas exceções, como a Academia de Ciências, o ensino das ciências estava muito distante das universidades da época e demais instituições de ensino. $\mathrm{O}$ modelo tradicional dos colégios, que valorizava o ensino de gramática e oratória, seria substituído por um modelo que focasse mais nas estruturas estatais e no seu progresso. As escolas francesas de nível superior criadas nesse momento ganham, então, certo enfoque profissionalizante para atender aos interesses do Estado.

A criação da École Normale provia subsídio para a formação de professores das escolas básicas. O seu papel era o de formar professores que pudessem capacitar os cidadãos nas escolas laicas a exercer uma mão de obra mais qualificada. A École Polytechnique e as Écoles d'Application foram exemplos para onde escoariam esses estudantes qualificados. Foram escolas voltadas para a formação imediata, emergencial de engenheiros. Houve duas direções de formação de engenheiros: uma civil, relacionada à infraestrutura do país, e outra militar, voltada para a defesa e a expansão da nação e dos ideais franceses.

A escola foi fundada no período mais difícil da Revolução Francesa, quando a desintegração de todos os institutos de educação e a perda contínua de jovens vigorosos treinados para fins militares criaram uma necessidade urgente para uma

\footnotetext{
${ }^{2}$ O "Plan Condorcet" está publicado em: Guillaume, James. Procès-verbaux du Comité d'Instruction Publique de l'Assemblée Législative, publiés et annotés (PARIS: Imprimerie Nationale, 1889).
} 
extensão nessa direção (...) A escola existiu para treinar oficiais para a Revolução, e mais tarde para o exército de Napoleão. (KLEIN, 1979, p.60)

A EP foi fundada em 1794 como fruto dessas transformações revolucionárias. Em um primeiro momento, sob o nome de École Centrale des Travaux Publics (Escola Central de Trabalhos Públicos) e rebatizada, no ano seguinte, para École Polytechnique. O objetivo da nova instituição foi preparar engenheiros, civis e militares, com o propósito de favorecer o desenvolvimento econômico independente da aristocracia. Seu ingresso dava-se exclusivamente por meritocracia, independente de sua classe social - o que representa o ideal igualitário francês.

Os investimentos governamentais e a administração da EP, num primeiro momento, favoreceram a escola a tornar-se rapidamente o maior polo de produção científica para a época. Essa combinação bem-sucedida resultou na concentração de matemáticos e físicos em uma única instituição como nunca antes. "Os melhores cientistas da França foram induzidos a dar seu apoio à escola; muitos grandes matemáticos franceses eram estudantes, professores ou examinadores na Escola Politécnica" (STRUIK, 1987, p. 146).

Esses investimentos foram responsáveis por práticas matemáticas particulares da própria escola. Foi uma instituição responsável por desenvolver uma matemática moderna. Ao mesmo tempo, destaca-se também por ter sido pioneira em produzir uma matemática voltada para o ensino. Pode-se dizer que esses dois aspectos possuem uma relação simbiótica. A matemática que se propunha a ensinar na EP exigia uma produção didática, enquanto que a produção didática influenciava na própria prática matemática. Isso porque a matemática praticada no ensino, geralmente, era herdeira da matemática grega clássica, que não oferecia subsídios para o desenvolvimento das práticas até então contemporâneas das ciências emergentes.

\section{Método analítico}

Em primeiro lugar, precisamos definir a que nos referimos quando dizemos que a EP desenvolvia uma matemática moderna. Nesse sentido, precisamos lembrar que a matemática ensinada durante o Antigo Regime foi somente em escolas secundárias, nos colégios principalmente dos Jesuítas - e que não existiu na França um ensino de matemática no nível superior (SCHUBRING, 2005). A matemática desses colégios constituía na reprodução de saberes clássicos de modo que seus objetivos não eram um desenvolvimento da matemática ou uma busca por novas ferramentas. Pelo contrário, eram caracterizadas por uma postura 
conservadora dos métodos dos antigos, como um saber superior, distante, idealizado, quase como um saber místico. Não se tratava, nesse sentido, de um ensino especializado voltado, por exemplo, para as práticas da física e da matemática, mas de um ensino generalizado.

As universidades nesse período não tinham qualquer propósito de preparar engenheiros, como era o da EP. A matemática toma sua importância nessa instituição pela série de técnicas que envolviam a resolução de problemas. A própria EP fundamentou-se na ideia de que a matemática, junto à química, constitui um conjunto de teorias a serem aplicadas às ciências. Ela tornou-se o principal instrumento para desenvolver a forma de pensar e de resolver problemas. Isso justificou o motivo pelo qual a matemática fora adotada como disciplina fundamental no curso de engenharia da escola.

Por outro lado, o método analítico tinha como uma de suas bandeiras a busca por novas verdades. Trata-se de uma ferramenta para descobrir (ou construir) novas propriedades matemáticas, o que o método sintético clássico não conseguiria estabelecer. A principal crítica ao método sintético, feita muito antes da fundação da EP, seja por René Descartes (15961650) ou por Gottfried von Leibniz (1646-1716), era que esse não oferece meios intuitivos para obterem proposições matemáticas (ROQUE, 2012, p. 317-318). Ele não apresenta explicitamente o modo como se constroem os passos para serem formuladas novas verdades, mas sim um método artificial para justificar propriedades já sabidas.

Portanto, o método analítico teve papel primordial na EP, sendo responsável por esse caráter de desenvolver-se a descoberta, ao mesmo tempo em que a algebrização do método permitiria um grau maior de generalidade nas descobertas. Esse perfil encaixa-se convenientemente na ideia de que a formação na EP deveria ser a mais abrangente possível para um curso de engenharia. Consequentemente, a escola tornou-se responsável, em grande parte, pela difusão e legitimidade do método analítico.

Contudo, convém ressaltar que essa característica da EP - valorização do método analítico sobre o método sintético - dá-se somente nos primeiros anos de atuação da escola. A pretensão desse método de abranger toda a teoria e as práticas da matemática, desenvolvida e ensinada na EP, foi um dos fatores responsáveis por crises na estrutura do curso na escola. Essas crises resultaram, posteriormente, na adoção do método sintético no ensino, que é um fato importante para a história da matemática.

\section{Estrutura da Escola Politécnica}


A EP foi um exemplo bem sucedido de ensino de teoria e aplicação. Podemos identificar esse nível de sucesso, pois até hoje existe uma influência da EP na criação de cursos de engenharia. Muitas instituições voltadas para a formação de engenheiros seguem o modelo francês. Esses traços vão além do próprio nome que tais instituições foram batizadas, já que diversas instituições seguem tradicionalmente o nome de "escola politécnica", ao invés de faculdade ou instituto de engenharia. Eles também pode ser observados pela sua estrutura curricular. Os cursos normalmente são compostos por um ciclo básico de 2 anos, comum a todas as engenharias, envolvendo majoritariamente o ensino de matemática, física e química, enquanto que os anos seguintes de curso são voltados para a especialização em uma área de engenharia.

A França foi pioneira nesse modelo de ensino e a EP consistiu uma espécie de ciclo básico do curso de engenharia. Lá os estudantes entravam em contato com os conhecimentos necessários para uma ampla gama de especialidades de engenharia da época. Após normalmente três anos de estudo, os estudantes eram direcionados a outras escolas de nível superior, chamadas de escolas de aplicação, sendo elas: École d'Artillerie, École du Genie; École des Ponts et Chaussées, École des Mines e École des Géographes (Escola de Artilharia, Escola de Engenharia Militar, Escola de Pontes e Estradas, Escola de Minas e Escola de Geografia). Essas escolas seriam responsáveis por definir o foco da formação do estudante de engenharia, seja para fins militares ou civis. A EP ficou encarregada, desde a primeira reorganização em 1795, de preparar os estudantes de engenharia para essas escolas. Esse fato tem grande importância, pois ele foi o pivô de crises que a EP atravessava a respeito dos conteúdos que nela deveriam ser ministrados (SCHUBRING, 2005).

A matemática moderna que a EP se propunha a ensinar, por vezes, não possuía sólidos fundamentos. Em alguns casos, os professores que se propunham a ensinar eram exigidos que fizessem suas próprias fundamentações teóricas. No campo da análise matemática foi bem evidente essa produção de material na EP. Essa disciplina foi tratada como um dos pilares do ensino politécnico. O termo era entendido como uma forma de algebrização com o rigor matemático francês dos séculos XVIII e XIX. Por exemplo, pode ser visto nas três grandes áreas da EP: "analyse apliquée à la geometrie", "analyse appliquéé à la mécanique" e "analyse appliquée aux calculs des effets dês machines" (SCHUBRING, 2005, p. 295-296). Devido à falta de experiência com tal programa abrangente de ensino da matemática, revelou-se que os alunos deviam ser ensinados uma introdução à análise seguindo o famoso livro-texto de Euler. Foi Fourier, como colaborador de ensino, que foi encarregado de ministrar tal curso desde 
1795. ${ }^{3}$ A disciplina também possuía uma certa independência e alguns trabalhos em destaque podem ser citados, como é o caso de Cours d'Analyse algébrique, de Cauchy (1821) (CAUCHY, 1989) e Théorie des fonctions analytiques (1800) e Leçons sur le calcul des fonctions de Lagrange (1806). Contudo, esses exemplos são exceções se comparados a outras publicações da EP.

Sob pressões institucionais, lideradas pelos Corps du Génie, a corporação dos engenheiros militares e de artilharia, e das próprias reestruturações internas entre 1797 e 1800 , o ensino de matemática mudou decisivamente o seu enfoque. Depois da ruptura fundamental com as concepções originais, acontecida em 1811, deve-se constatar:

\begin{abstract}
A École Polytechnique deveria entregar todos os cursos de aplicação para as escolas de aplicação, ela estava restrita à educação geral de engenheiros. Qualquer outro propósito que fosse além disso, por exemplo uma educação científica, foi rejeitada. (SCHUBRING, 2005, p. 300)
\end{abstract}

Desde sua criação, as disciplinas ministradas na EP foram caracterizadas por uma união entre teoria e prática. Os estudantes deveriam entrar em contato com as disciplinas básicas para uma formação de engenharia, aprendendo os conhecimentos necessários que todo engenheiro deveria dominar. Seriam conhecimentos voltados para o ofício do engenheiro, constituindo-se num arcabouço teórico que não deveria se distanciar de suas aplicabilidades. Contudo, nos primeiros anos de sua fundação, muitas vezes a EP fugia a essa regra.

\title{
6 A matemática nos primeiros anos de EP
}

\begin{abstract}
A ascensão da espacial geometria consequentemente foi devido, em parte, às atividades matemáticas e revolucionárias de Gaspard Monge. Se ele não tivesse sido politicamente ativo, a École Polytechnique poderia nunca ter surgido; se ele não tivesse sido um inspirador professor, o renascimento da geometria em três dimensões pode não ter ocorrido. (BOYER, 1989, p. 532)
\end{abstract}

Monge é referenciado recorrentemente como fundador da EP tanto nos textos clássicos de história, como pelo relato de Klein: "Se olharmos para o homem que criou essa obra de arte, precisamos olhar para o geômetra e administrador Monge (1746-1818) que, até sua morte, foi a real força motivadora desse grande trabalho" (KLEIN, 1979, p. 68) No entanto, vale ressaltar que desde a mudança em 1800 para a "escola de Laplace" - como a EP ficou conhecida no início do século XIX pela historiografia - Monge não foi mais a força motivadora. Inclusive, fora aposentado pela escola em 1810. Depois ainda da restauração da

\footnotetext{
3 As notas de aula que o aluno Charles-Louis Donop fez deste primeiro curso de Fourier foram publicadas, baseadas no manuscrito preservado, em 1989 (LORRAIN, 1989).
} 
monarquia em 1815, Monge - como régicide - foi isolado e não pôde exercer qualquer influência na EP.

Monge é uma peça fundamental na criação da geometria projetiva. Suas demais contribuições matemáticas também lhes dão um papel de destaque na história da matemática. Talvez, por conta de sua reputação, seja um dos principais pivôs utilizados na historiografia da matemática para justificar a forte presença da matemática no ensino da escola. Não parece conveniente retirar os méritos do geômetra francês pela organização dos primeiros anos de funcionamento. De fato, Monge pode ser atribuído como um dos grandes idealizadores da formulação politécnica focada no ensino da matemática. Mesmo pesquisas atuais confirmam a sua posição de destaque em conceitualizar a EP e em transformar as idéias em prática.

A influência de Monge certamente foi além de seu papel administrativo. Monge é responsável por uma forte escola de geometria que fugia aos padrões clássicos. Por conta de seu impacto original às concepções da escola e o prestígio que gozava na matemática superior, a geometria acabou ganhando uma característica bastante peculiar na escola.

\begin{abstract}
Além disso, a géometrie descriptive teve uma função particularmente distinta, porque ela encorpa a unidade social na divisão do trabalho entre teoria e prática. No primeiro currículo, não foram separados assuntos que não foram planejados, mas realizações concretas integradas ao conceito da analyse. (SCHUBRING, 2005, p. 295)
\end{abstract}

No entanto, o papel da geometria não foi parte do eixo central do ensino na EP, como Klein nos faz crer: "Foi por conta de sua extraordinária atividade bem sucedida como administrador e professor que a geometria fora o centro de instrução durante os primeiros 20 anos da escola." (KLEIN, 1979, p. 71). O ensino na EP era composto por diversos aspectos, seguindo uma linha de unir a prática com a teoria. Como um contraexemplo, podemos citar o desenvolvimento do cálculo diferencial e integral pelo qual a escola teria contribuído significativamente; ou pela ênfase nas ciências aplicadas, como na física e na química, pela qual se priorizava no ensino politécnico.

\title{
7 Produção acadêmica
}

"Talvez o mais antigo dos periódicos correntes, dedicados principalmente ou inteiramente à matemática avançada, seja o francês Journal de L'École Polytechnique, lançado em 1794.” (EVES, 2004, p. 565) Acredita-se que a EP veio a se tornar um berçário da produção acadêmica do século XIX porque a própria escola providenciava condições que favoreciam esse reflexo. Uma delas estava presente na criação do Journal de l'École 
Polytechnique. "A influência externa da escola foi ampliada pela regra que as aulas deveriam ser publicadas" (KLEIN, 1979, p. 61). Porém, ambas as afirmações encontram contradições frente a pesquisas recentes.

Se analisarmos os primeiros anos de publicação do periódico, podemos identificar diversos artigos de caráter científico e experimental, além de memórias e notas históricas da instituição. Porém, suas publicações mais características tinham propósitos didáticos. Diversas lições de aula enriqueceram os cadernos publicados nos mais diversos campos, além da matemática. Com base nas informações contidas nesses periódicos podemos traçar um perfil dos primeiros anos da escola.

Dividimos as publicações dos cadernos de acordo com as seguintes áreas, levando a área de atuação do autor de cada obra e a seção em que cada artigo constava. Escolhemos então classificar as publicações em : matemática, que inclui stéréotomie, análise, geometria e aritmética; física, que inclui por sua vez física geral, mecânica, ótica e statique; química, que inclui mineralogia; engenharia , que inclui arquitetura civil, fortificação e hidrografia; desenho, que inclui dessin e também arts e metiers; por fim, um categoria genérica para agregar os demais artigos que chamados de outros: economia, biografias, memória da instituição, regimento da escola, etc. Logo, os artigos ficam distribuídos:

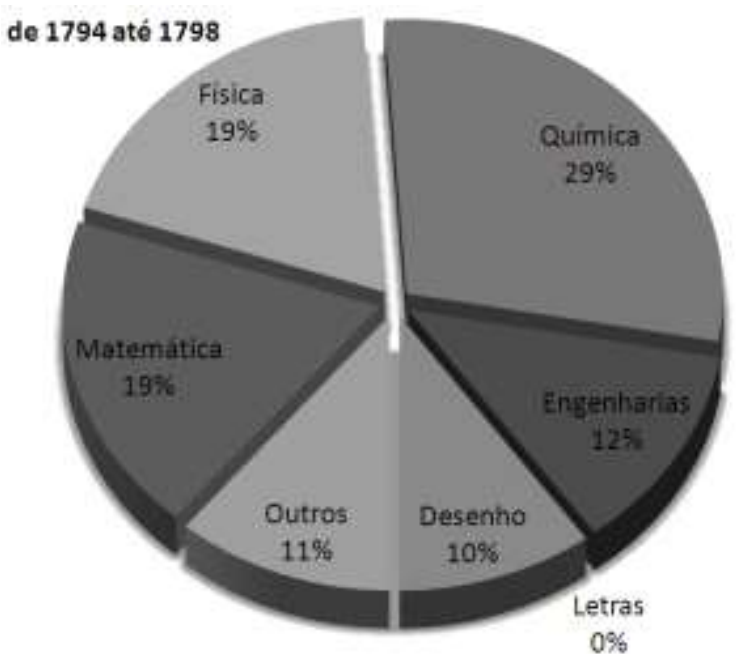

Gráfico 1 - Publicações da EP de 1794 a 1798

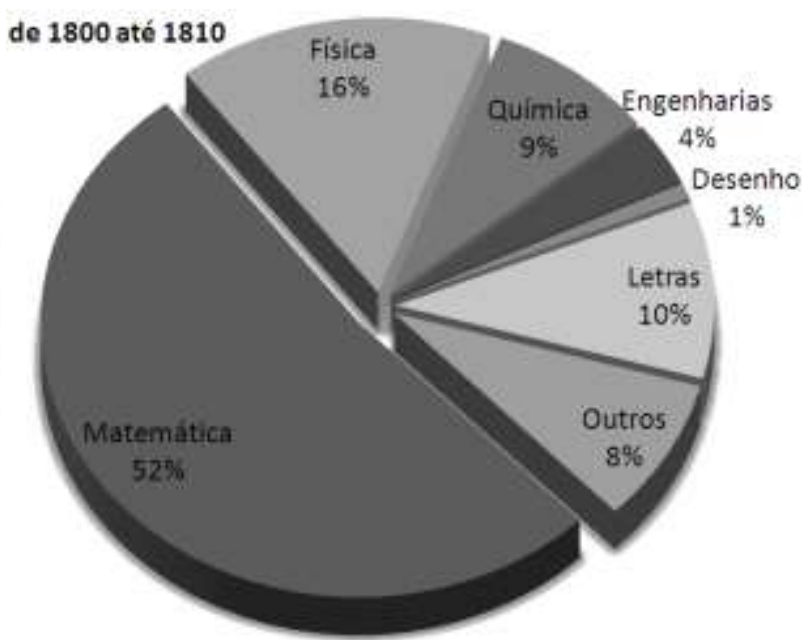

Gráfico 2 - Publicações da EP de 1800 a 1810

De imediato, podemos identificar que a matemática não pode ser tomada como eixo principal das publicações do Journal, pelo menos até a sua primeira crise, entre os anos de 1798 a 1800. Alguns artigos seguiam essa linha, contudo, em sua maioria eram vinculados desde aplicações na física e na química, a trabalhos nos campos da arquitetura e das construções militares. Portanto, podemos questionar se a matemática teria sido o foco central da escola, ou seria uma disciplina básica na formação do engenheiro formado pela EP. 
Um fato importante a respeito da escola é que a escola de Monge - como a EP é conhecida nos seus primeiros anos - perde a sua força, dando espaço para um novo perfil de escola. A escola atravessa sua primeira crise na sua organização e adota um perfil mais voltado para a análise matemática. Muitas cadeiras voltadas para a matemática aplicada passariam a fazer parte das escolas de aplicação. A partir de 1799/1800, a escola passa a ser conhecida como escola de Laplace, não mais como escola de Monge. O método analítico é substituído pelas disciplinas de análise, isto é, análise no sentido de uma disciplina, não mais como um método. É curioso que nesse período pós-Monge, de 1800 a 1810, a Escola Politécnica adquire um perfil mais fiel à primeira descrição da escola por Delambre.

Seguindo a regra de que os professores da EP tiveram a obrigação de converter seus cursos ministrados na escola em notas de aula, pode-se levar a crer que muitas dessas notas foram convertidas em livros didáticos. Contudo, recorrendo a pesquisas atuais encontramos evidências que não sustentam essa ideia:

\begin{abstract}
Entre outras inovações, a partir de 1806 os registros foram feitos, geralmente por um administrador $^{4}$, do conteúdo por assunto (embora raramente também com método) de cada aula em um curso. Estes registros de instrução são um recurso histórico valioso, como complemento das informações nos programas sobre o conteúdo do ensino; são agora mantidos como volumes manuscritos nos arquivos da escola. (GRATTAN-GUINNESS, 2012, p. 222)
\end{abstract}

Ou seja, somente a partir de 1806 que as aulas foram registradas 5 . Porém, com os registros tardios aos 12 primeiros anos desde fundação da EP, a escola foi responsável pela alta produção de livros textos ou acadêmicos:

Os politécnicos foram responsáveis por diversos livros na década seguinte [ 1800].
Muitos deles foram textos eminentemente bem sucedidos, aparecendo em diversas
edições. (...) o de Lacroix (...) apareceu em vinte e cinco edições em nove anos!
Talvez nós devêssemos falar de "revolução de livros textos". (BOYER, 1989, p.
$535)$

Em toda a vida de Lacroix - que foram muito mais do que 9 anos - o Tratado Elementar, a qual Boyer se refere, teve somente cinco edições (em 1802, 1806, 1816, 1828, 1837). Esse trecho revela com clareza a necessidade de se rever algumas concepções engessadas na história da matemática. O que nos leva a outra questão pertinente à produção acadêmica e relativa à qualidade dessas produções.

Para desconstruir a ideia de que, de modo geral, os textos da EP possuíam uma relevância nas produções matemáticas da época, atacaremos um dos pilares do ensino

\footnotetext{
${ }^{4}$ Pesquisas ainda mais recentes apontam que os registros eram feitos pelos próprios professores (ver GILAIN 1989).

5 Porém, para os cursos "revolucionários" do primeiro ano, 1794, os registros foram publicados no Journal polytechnique, sob o nome “Résumé des leçons de ...” (ver LANGINS, 1987, pp. 114).
} 
politécnico: o cálculo diferencial e integral. Nesse sentido, os livros de Cauchy e Lagrange, destacados anteriormente, são ótimos exemplos de publicações bem sucedidas no desenvolvimento da matemática, mas que podem esclarecer alguns questionamentos sobre a alta qualidade dos textos da escola.

Quando Lagrange fora convidado a lecionar na EP, a escola ainda estava em seus primeiros anos de funcionamento. Pretendemos colocar em pauta se esses trabalhos podem ser considerados genuinamente publicações da escola. Em primeiro lugar, Lagrange nunca se tornou um professor efetivo da EP. Ele ministrou apenas dois cursos na instituição e aceitou lecionar as disciplinas sob a condição de que seus alunos fossem escolhidos pelos seus bons desempenhos acadêmicos. Esses cursos foram fundamentais para a elaboração de duas obras bastante relevantes na produção textual da época: Théorie des fonctions analytiques (Teoria das funções analíticas) de 1797 e Leçons sur le calcul des fonctions (Lições de cálculo de funções) de 1800. Porém, não foram cursos ordinários da escola e tampouco por um professor efetivo da própria instituição. Por fim, os livros de Lagrange tiveram aplicação como recurso para cientistas, não para os alunos (FOURCY, 1987, p. 158).

Em termos de utilização nos cursos de cálculo diferencial e integral, as obras de Lacroix se demonstraram mais recorrentes: ele teve publicado o Traité de calcul differéntiel et du calcul intégral (Tratado de cálculo diferencial e de cálculo integral) - uma obra de referência para a matemática - em três volumes, o primeiro lançado em 1797, o segundo em 1798 e o terceiro em 1799. Esta obra, representando o estado mais avançado da pesquisa, então de tipo "handbook", não foi destinado ao ensino. Porém em 1802, Lacroix publicou uma versão mais condensada, Traité élémentaire de calcul differéntiel et du calcul intégral (Tratado elementar de cálculo diferencial e de cálculo integral) servindo como livro texto. O Tratado Elementar foi utilizado como livro padrão nos cursos de análise da EP nos anos em que Lacroix foi o professor e também para seus successores. Os registros do curso de análise destes anos indicam simplesmente os números dos parágrafos deste livro como conteúdo da respectiva aula.

\footnotetext{
Alguns dos melhores livros textos do início do século XIX foram preparados para a instrução na Escola Politécnica ou instituições similares. Suas influências podem ser rastreadas em nossos textos atuais. Um bom exemplo de um livro é o Traité du calcul différentiel et du calcul integral (2 vol., 1797), escrito por Sylvestre-François Lacroix, a partir do qual gerações inteiras aprenderam calculo. (STRUIK, 1987, p. 147)
}

O fato de Lacroix ser adotado nos cursos da EP nos oferece uma certa dose de ironia. Apesar dos esforços para se desenvolverem materiais próprios da escola, como a criação do Journal de l'École Polytechnique e das notas de aula sendo obrigatoriamente publicadas, o 
fundo do livro utilizado nos cursos de cálculo, o livro de Lacroix, não foi da produção da própria escola. O livro de Lacroix tem como origem experiências anteriores à EP. "No ano de 1799, em sua idade avançada, Lagrange foi substituído por S.-F. Lacroix (1765-1843), o maior escritor de livros textos de seu tempo." (GRATTAN-GUINNESS, 2012, p. 222) Ou seja, Lacroix ingressou como professor da EP somente após a publicação de seu tratado de três volumes - não dois como sugere a citação anterior de Struik - sobre cálculo diferencial. $\mathrm{O}$ que, portanto, evidencia que a produção do grande Tratado foi independente de seu trabalho na EP. Contrariamente à afirmação de Struik, não foi o grande Tratado "a partir do qual gerações inteiras aprenderam cálculo”. Convém ressaltarmos que Lagrange não fora nesse momento professor efetivo da EP. Ele assumia uma cadeira semelhante a de um professor visitante para nós. Lacroix ingressa na escola em 1799 exercendo essa mesma posição que seu antecessor. Somente em 1802 que Lacroix seria efetivado como professor da escola no lugar de Garnier, mesmo ano em que seu bem sucedido livro fora transformado em livro-texto para o curso de análise.

Por outro lado, Gaspard de Prony (1755-1839) pode ser reconhecido como um autor próprio da EP. Sua mais relevante obra no campo da análise, Cours d'analyse appliquée à la mécanique (Curso de análise aplicado à mecânica) foi publicada no Journal de l'École Polytechnique em 1794 como fruto de suas aulas na escola, e a segunda parte deste curso, Suite des leçons d'analyse (Lições de análise), foi publicado também no Journal, em 1795. Contudo, jamais tivera o respaldo que os textos de Lacroix.

Com alguns anos de diferença, o livro de Cauchy é outra obra que aparece em destaque: Cours d'analyse algébrique (Curso de análise algébrica) publicado em 1821. Assim como os textos de Prony, o trabalho de Cauchy parece ter sido uma obra genuinamente da escola. Ela é fruto de suas aulas e reflexões baseadas em uma busca por um refinamento dos fundamentos do cálculo. Ao mesmo tempo, a obra parece ter experimentado uma repercussão histórica comparável a de Lacroix, ainda que em outro sentido. Contudo, a grande obra de Cauchy, sendo adotada somente por um ano pela escola (GILAIN, 1989, p. 13), se demonstrou um fiasco nos seus cursos pelo fato de ter sido detestado pelos alunos (BELHOSTE, 1985, pp. 81-85).

A obra de Cauchy entra para a história da matemática por motivo de cunho epistemológico. Nela podemos identificar uma fundamentação do cálculo semelhante aos fundamentos que utilizamos hoje, motivo principal que a historiografia faz seus elogios à sua obra. 
Observando uma análise global sobre essas obras, observamos que entre a publicação das primeiras lições de cálculo da EP com Prony (1794/95) com o de Cauchy (1821), há uma diferença de 26 anos. Temos assim um longo intervalo sem publicações nesse assunto. Ou seja, se temos como destaques significativos essas obras e se não podemos afirmar que elas são produções propriamente da EP, então parece surgir uma discrepância considerável entre o que os autores de história da matemática assumem como alta produção, no que se refere aos livros de cálculo e análise, em contraste com as evidências que nos surgem.

\section{Considerações finais}

Esse exemplo da EP mostra-nos que a contraposição de mitos com fatos requer uma pesquisa em fontes e metodologias adaptadas a fim de se conseguir entender o funcionamento de uma instituição superior em um contexto mais amplo.

A escola estava inserida em um ambiente favorável a uma alta produção intelectual nos campos das ciências, em especial para nós, da matemática. Isso não significa de maneira nenhuma que outras instituições deveriam ser esquecidas. Professores da EP podiam tornar-se também membros da Academia, para tarefas de pesquisa. Foi bastante recorrente professores acumularem posições em diferentes institutos, em particular, nos emergentes facultes dês sciences, do nível do ensino superior. Não precisamos indicar que a escola foi fruto de um acontecimento singular, mas que fez parte de um conjunto de fatores que levou a matemática do início do século XIX a considerar Paris como sua capital. Não teria sido a escola a principal responsável, mas a combinação das circunstâncias políticas e epistemológicas sobre a matemática como um sustentáculo das ciências.

Nosso objetivo não foi o de ressaltar que a École Polytechnique foi determinante na produção matemática da França do século XIX - isso as referências tradicionais citadas já o fazem - mas o de explorar como isso se dá e determinar as influências institucionais que os matemáticos relacionados à EP sofreram, seja pelas práticas da época, seja pelos objetivos da escola, seja pelas pressões sociais que sofria a França durante o seu período de revolução. Essas influências definiam as produções acadêmicas da escola e, portanto, o desenvolvimento da própria matemática nela. Sendo assim, a EP é um exemplo perfeito de como podemos defender a tese de que o desenvolvimento da matemática se dá muito mais por um esforço coletivo.

A releitura de um relato dos primeiros anos de funcionamento da EP tão próximo a sua época surge como um exercício de revisão dos próprios textos clássicos de história da 
matemática. Os contrastes e as semelhanças entre esses dois tipos de textos fazem-nos buscar outras fontes que sustentem um dos lados. O que nos surpreende não é quando encontramos evidências que sustentem apenas um dos lados, mesmo que o revelado vá contra as nossas certezas. O que abala profundamente nossas crenças é quando as evidências indicam que nenhum dos lados estava correto, ainda que tenham a mesma opinião.

A alta produção de livros pela EP (BOYER, 1989) é um exemplo conveniente desse caso, em que os textos clássicos e o texto de Klein confirmavam uma concepção exagerada do que poderia ter sido a produção de textos referentes à EP. A posição de Monge, certamente, foi um fator fundamental para a formação inicial da instituição, mas poderíamos entender que ele estava no lugar certo, na hora certa quando a Revolução eclodiu.

Podemos perceber que, quanto mais buscamos fontes para fundamentar nossas certezas, menos certos ficamos sobre elas e, portanto, mais afundados em questionamentos.

\section{Referências}

BELHOSTE, B. Cauchy 1789-1857: Un mathématicien lêgitimiste au XIXe siècle. Paris: Belin, 1985.

BELHOSTE, B. Augustin-Louis Cauchy: a biography. New York: Springer, 1991.

BELHOSTE, B. De l'Ecole des ponts et chaussées à l'Ecole centrale dês travaux publics. Bulletin de la Société des Amis de l'École polytechnique n. 11, feb. 1994.

BLAINEY, G. Uma breve história do mundo. São Paulo: Editora Fundamento Educacional, 2008.

BOYER, C. B. A history of mathematics. 2. Ed. New York: John Wiley \& Songs, 1989.

CAUCHY, A.-L. Cours d'analyse algébrique. Paris: Éditions Jacques Gabay, 1989. Nota: re-edição da versão original de 1821 .

DELAMBRE, J. B. Rapport historique sur les progrès des sciences mathématiques depuis 1789. Paris: Imprimérie Impériale, 1810.

DHOMBRES, J.; ROBERT, J. B. Fourier: crêateur de la Physique-Mathématique. Paris, Belin: 1998.

DOOLEY, E. L. Procès verbaux des Séances du Conseil de l'Ecole polytechnique. Bulletin de la Société des Amis de l'École polytechnique, n. 12, nov. 1994.

EVES, H. Introdução à história da matemática. Campinas: Editora da Unicamp, 2004.

FOURCY, A. Histoire de l'Ecole Polytechnique. Paris: Belin, 1987. Nota: Reedição de J. Dhombres.

GILAIN, C. Augustin-Louis Cauchy 1789-1857: Cauchy et le Cours d'analyse de l'École polytechnique. Bulletin de la Société des Amis de l'École polytechnique, n. 5, juil. 1989. 
GRATTAN-GUINNESS, I.; RAVETZ, J. Joseph Fourier (1768-1830): a survey of his life and work, based on a critical ed. of his monogr. on the propagation of heat, presented to the inst. de France in 1807. Cambridge, Massachusetts: MIT Press, 1972.

GRATTAN-GUINNESS, I. Convolutions in French Mathematics, 1800-1840: From the Calculus and Mechanics to Mathematical Analysis and Mathematical Physucs. Basel: Birkhäuser, 1990. 3 volumes.

GRATTAN-GUINNESS, I. On the role of the Ecole Polytechnique 1794-1914, with especial reference to mathematics. In: BUCHWALD, J. Z. (Ed.). A master of science history. New York: Springer, 2012. (p. 217-234) (New studies in the history of science and technology, v. 30)

LAGRANGE, J.-L. Leçons sur le calcul des fonctions. Paris: Courcier, 1806. Nota: nova edição revisada, corrigida e comentada pelo autor.

LAGRANGE, J.-L. Théorie des fonctions analytiques. Paris: De l'Imprimerie de la République 1800 .

KLEIN, F. Development of Mathematics in the 19th Century. Trad. M. Ackerman do original Vorlesungen uber die Entwicklung der Mathematik im 19 Jahrhundert (1928) Massachusetts: Math Sci Press, 1979.

LANGINS, J. La République avait bésoin de savants. Paris: Belin, 1987.

LORRAIN, Anne-Marie, éd. Jean-Baptiste Joseph Fourier: Leçons d'un cours d'analyse rédigées par C. L. Donop (Ms. Vitt. Em. 1509). Ferrara: 1989. (Quaderni di storia delle matematiche; Dipartimento di Matematica dell’Università di Ferrara)

ROQUE, T. História da matemática: uma visão crítica, desfazendo mitos e lendas. Rio de Janeiro: Zahar Editora, 2012.

SCHUBRING, G. Le Retour du Refoulé. Der Wiederaufstieg der synthetischen Methode an der École Polytechnique. Reihe Algorismus, Augsburg: Erwin Rauner, 2004.

SCHUBRING, G. Conflicts between generalization, rigor, and intuition: number concepts underlying the development of analysis in 17th-19th century France and Germany. New York: Springer, 2005. (Sources and studies in the history of mathematics and physical sciences)

STRUIK, D. A concise history of mathematics. 4. Ed. New York: Dover Publications, 1987. 